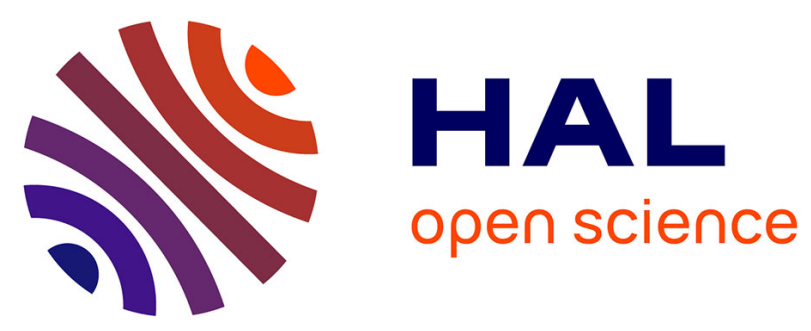

\title{
3-D TCAD Assessment of Fin-Based Hybrid Devices Under Heavy Ion Irradiation in 20-nm Technology
}

Kumar Prasannajit Pradhan, Samar K. Saha, Laurent Artola, Prasanna Kumar Sahu

\section{- To cite this version:}

Kumar Prasannajit Pradhan, Samar K. Saha, Laurent Artola, Prasanna Kumar Sahu. 3-D TCAD Assessment of Fin-Based Hybrid Devices Under Heavy Ion Irradiation in 20-nm Technology. IEEE Transactions on Device and Materials Reliability, 2018, 18 (3), pp.474-480. 10.1109/TDMR.2018.2865090 . hal-02176287

\section{HAL Id: hal-02176287 \\ https://hal.science/hal-02176287}

Submitted on 8 Jul 2019

HAL is a multi-disciplinary open access archive for the deposit and dissemination of scientific research documents, whether they are published or not. The documents may come from teaching and research institutions in France or abroad, or from public or private research centers.
L'archive ouverte pluridisciplinaire HAL, est destinée au dépôt et à la diffusion de documents scientifiques de niveau recherche, publiés ou non, émanant des établissements d'enseignement et de recherche français ou étrangers, des laboratoires publics ou privés. 


\title{
3-D TCAD assessment of fin based hybrid devices under heavy ion irradiation in 20-nm technology
}

\author{
K P Pradhan, Member, IEEE, Samar K. Saha, Senior Member, IEEE, L Artola, Senior Member, IEEE, P K \\ Sahu, Senior Member, IEEE
}

\begin{abstract}
In this paper, the single event transient response in nanometer hybrid FinFETs like Wavy and Symmetric Dual- $k$ Spacer (SDS) Wavy FinFETs are systematically investigated. The novel SDS Wavy FinFETs consist of an ultra-thin body (UTB), FinFET, and spacer engineering on a single silicon-on-insulator (SOI) platform. Three-dimensional quantum simulations are used to study the heavy ion irradiation on $20 \mathrm{~nm}$ n-type hybrid devices. The physical insight on the post ion irradiation of the devices are carefully observed and compared with the conventional FinFETs. The effects of heavy ion irradiation on various parameters including current density, ion generation, transient current, and bipolar amplification are estimated. Furthermore, the post-ion irradiation is also examined as a function of ion characteristic time and ion-track radius.
\end{abstract}

Index Terms-Wavy FinFET, Dual- $k$ spacer, heavy ion, transient current, bipolar amplification.

\section{INTRODUCTION}

As the scaling of CMOS technology continues, the threedimensional (3-D) FinFET became a feasible alternative to the traditional single gate devices. The invention of FinFET has enabled the continued advancement of electronics industry and is of immense interest for sub-20 nm applications [1], [2]. The fin based devices are excellent in suppressing the short channel effects (SCEs) and have superior control over the carriers in the channel [3]-[7]. Henceforth further modification and continuous research on Fin based devices have been going on for over a decade. Out of these research efforts, the hybrid FinFETs are of great interest that was initially proposed by Mathew et al. [8] and Zhang et al. [9] as an inverted-T FET. Hybrid FinFETs merge several technologies in a single SOI platform namely three dimensional (3-D) FinFET and two dimensional (2-D) ultra-thin body (UTB) MOSFET as reported by Fahad et al. [10], [11]. In order to analyze the impact of high- $k$ spacer technology in the hybrid FinFETs, Pradhan et al. [12]-[14] have quantitatively explored the effect of high- $k$ spacer length on various performance matrix of the hybrid devices. This work presents a systematic analysis on the reliability aspects of the hybrid FinFETs and carefully

K P Pradhan is with Indian Institute of Information Technology Design and Manufacturing (IIITDM), Kancheepuram, Chennai, 600127, India (e-mail: k.p.pradhan@ieee.org)

P K Sahu is with the National Institute of Technology, Rourkela, Odisha, 769008, India (e-mail: pksahu@nitrkl.ac.in).

S K Saha is with Prospicient Devices, Milpitas, CA - USA (e-mail: samar@ieee.org).

L Artola is with ONERA, 31055 Toulouse, France (e-mail: laurent.artola@onera.fr).

Manuscript received April 09, 2018; revised June 06, 2018 observed the single event transients (SET) for the considered devices.

It is well-known that the reliability of electronic devices designed for space and atmospheric applications are severely affected by radiations and this effect is continuously increasing due to the continuous shrinkage of devices [15]. In nanoelectronics, the natural radiation is one of the major causes of failure in device reliability [16], [17]. In order to improve reliability, Silicon-on-insulator (SOI) circuits and devices are widely used in aerospace/military applications due to their high exposure resistance against transient radiation effects such as Single Event Effects (SEE) (or) Single Event Upset (SEU) [18]. Typically, the radiation effects are induced due to the interaction of ionizing particle like heavy ion, neutrons and protons with the electronic devices [19]-[21]. If such an ionizing particle penetrates the reverse biased junction, depletion region and the bulk silicon of the device, then a plasma track is produced along its path resulting in a generation of electron-hole pairs. During this ion track, depletion layer of the device is distorted in its vicinity and creates a transient current. The distortion of the depletion layer is known as funnel which extends the layer along the ion track in such a way that the electrons move towards the junction and holes move to the grounded substrate resulting in a generation of substrate current. The electrons are collected at the drain contact leading to transient current that changes the logic state of the node. If a heavy ion penetrates into an integrated circuit, then it can cause multiple bit upset (MBU) [18]. However, SOI devices are less susceptible to radiation due to the presence of buried oxide (BOX) layer between the silicon film layer and substrate [22]. Hence, the charges generated in the substrate cannot be collected at the junction of the device resulting in less transient current compared to bulk devices. Since hybridFinFETs include SOI structure, it is of great interest to study the effect of terrestrial radiation on these devices for potential space application.

Hence, in continuation to the previous work [12]-[14], [23], this work systematically analyzes the reliability aspects of the n-type hybrid Wavy FinFETs. Moreover, the transient performances are evaluated when the devices are subjected to heavy ion irradiation. The current density before and after ion strike is explicitly discussed for the conventional FinFET (D1), Wavy FinFET (D2), and symmetric dual-k spacer (SDS) Wavy FinFET (D3). Further, the parameters like transient current, heavy ion generation, bipolar amplification for all three devices are primary focus of this study. Finally, the transient current is also investigated by varying the ion track radius, and 
ion characteristic time $\left(t_{\text {characteristic }}\right)$. Moreover, the primary objective of this work is to analyze the reliability aspects of all the devices when they are subjected to heavy ion irradiation. A comparison is made for the transient characteristics of all the devices under study before and after the ion strike to observe the device sensitivity towards heavy ion irradiation.

The organization of the paper is as follows: Section II describes the architectural differences of all three n-type devices i.e., conventional, Wavy, and SDS Wavy FinFETs. Section III explains the details of the transient simulations with feasible structures and models available in the device simulator Sentaurus ${ }^{T M}[24]$. The static characteristics for all three considered devices are investigated in section IV. Section IV also compares the impact of ion strike on internal device parameters, and the sensitivity towards heavy ion irradiation of the hybrid FinFETs with that of the conventional FinFETs in terms of transient current, and bipolar amplification. Finally, the concluding observations are well stated in section V.

\section{Device Architecture}

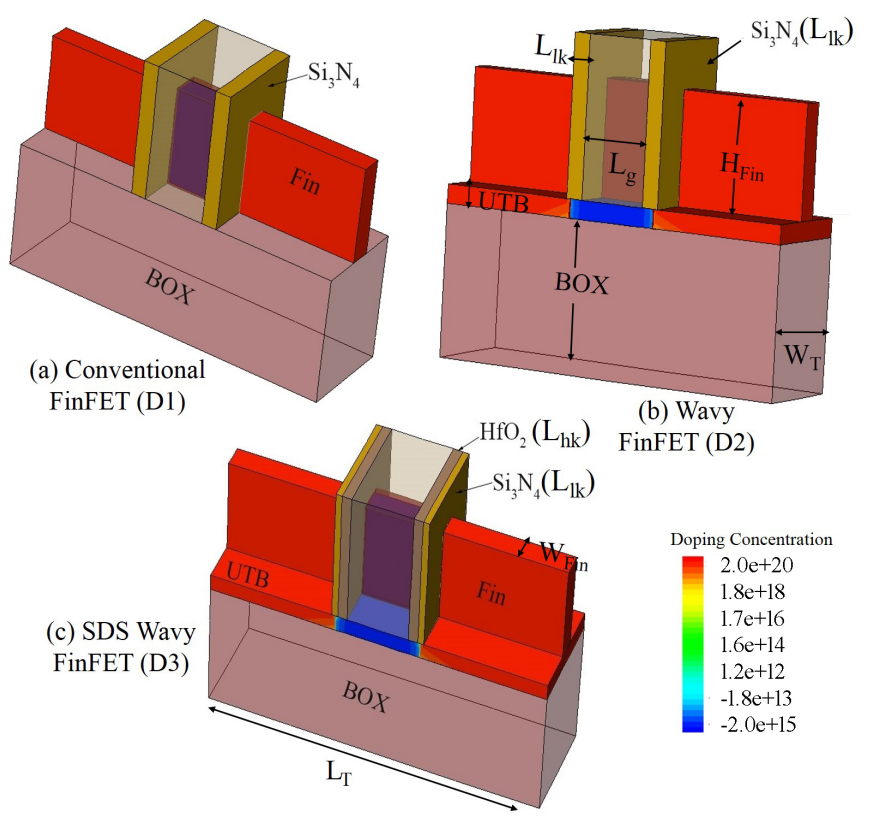

Fig. 1. (a) Schematic description of simulated conventional FinFET (D1), (b) Wavy FinFET (D2), and (c) SDS Wavy FinFET (D3). It should be noted that D1 does not include UTB layer and high- $k$ spacer material, while D2 does not include high- $k$ spacer only.

The 3-D geometries of the devices considered in this work are shown in Fig. 1. The structural uniqueness for all three devices is clearly shown in Fig. 11a), (b), and (c). Also, the proper design guidelines as per the ITRS road-map [16] are shown in Table $\left[\right.$ The silicon dioxide $\left(\mathrm{SiO}_{2}\right)$ equivalent oxide thickness (EOT) of $0.9 \mathrm{~nm}$ is considered as the gate oxide thickness and used for all numerical device simulation. The gate length $\left(L_{g}\right)$, and fin width $\left(W_{\text {Fin }}\right)$ are $20 \mathrm{~nm}$ and 7 $\mathrm{nm}$, respectively for all the devices. The hybrid FinFETs i.e., D2 and D3 consist of an extra UTB layer of $5 \mathrm{~nm}$ with equivalent fin height $\left(H_{\text {Fin }}\right)$ of $30 \mathrm{~nm}$ to maintain the constant area as of D1. An underlap length of $5 \mathrm{~nm}$ is considered from each side of the channel end towards source/drain,
TABLE I

THE DEFINITION OF GEOMETRICAL PARAMETERS CONSIDERED FOR DESIGNING AND ANALYZING THE 3-D DEVICES

\begin{tabular}{|c|c|c|c|c|}
\hline Symbols & Technology Parameters & $\begin{array}{c}\text { Conventional } \\
\text { FinFET (D1) }\end{array}$ & $\begin{array}{c}\text { Wavy } \\
\text { FinFET (D2) }\end{array}$ & $\begin{array}{c}\text { SDS Wavy } \\
\text { FinFET (D3) }\end{array}$ \\
\hline$W_{\text {Fin }}$ & Fin Width & $7 \mathrm{~nm}$ & $7 \mathrm{~nm}$ & $7 \mathrm{~nm}$ \\
\hline$H_{\text {Fin }}$ & Fin Height & $30 \mathrm{~nm}$ & $H_{\text {Fin }}$-UTB= $25 \mathrm{~nm}$ & $H_{\text {Fin }}$-UTB= $25 \mathrm{~nm}$ \\
\hline$L_{g}$ & Gate length & $20 \mathrm{~nm}$ & $20 \mathrm{~nm}$ & $20 \mathrm{~nm}$ \\
\hline UTB & Ultra thin body thickness & - & $5 \mathrm{~nm}$ & $5 \mathrm{~nm}$ \\
\hline $\begin{array}{c}\text { Spacer ratio } \\
\left(L_{h k}: L_{l k}\right)\end{array}$ & $\begin{array}{c}\text { Length of high- } k\left(H f O_{2}\right): \\
\text { Length of low- } k\left(S i_{3} N_{4}\right)\end{array}$ & $0: 5(\mathrm{~nm})$ & $0: 5(\mathrm{~nm})$ & $4: 1(\mathrm{~nm})$ \\
\hline EOT & Equivalent oxide thickness & $0.9 \mathrm{~nm}$ & $0.9 \mathrm{~nm}$ & $0.9 \mathrm{~nm}$ \\
\hline$L_{T}$ & Total device length & $110 \mathrm{~nm}$ & $110 \mathrm{~nm}$ & $110 \mathrm{~nm}$ \\
\hline$W_{T}$ & Total device width & $32.2 \mathrm{~nm}$ & $32.2 \mathrm{~nm}$ & $32.2 \mathrm{~nm}$ \\
\hline BOX & Buried oxide thickness & $40 \mathrm{~nm}$ & $40 \mathrm{~nm}$ & $40 \mathrm{~nm}$ \\
\hline
\end{tabular}

which is patterned with low- $k$ /high- $k$ spacer materials. Table II presents the technology and device parameters for all the devices. The SOI FinFETs [6] offer significant control over SCEs and electrostatic parameters with a vertical thin channel and also have lesser fabrication complexity compared to the bulk FinFETs [25]. FinFET and 2-D UTB technology are combined together to design the advanced hybrid topology i.e., Wavy FinFETs. It offers many advantages like maximum area efficiency, high packing density, and high drive current as reported in [9], [11]. The channel is lightly doped to avoid random dopant fluctuation (RDF) effect [1]. The metal gate technology is used to eliminate the poly-Si gate depletion effects [26]. For better comparison among the devices with different architectural configurations, the threshold voltage $\left(V_{t h}\right)$ is maintained the same at an approximate value for all devices by carefully tuning the gate metal work function. According to the previously reported data [13], [27], the device performance improves significantly with the increase in the high- $k$ spacer length $\left(L_{h k}\right)$. Hence, in this work the $L_{h k}: L_{l k}$ ratio is considered to be fixed at 4:1 for the SDS Wavy FinFET case.

\section{Simulation Procedure}

The 3-D numerical simulation using Sentaurus TCAD [24] from Synopsys Inc. have been systematically carried out for designing the devices. In order to generate accurate simulation results, the device model parameters are calibrated with the published data [10]. The default carrier transport model, i.e., drift-diffusion model along with the mobility model accounts for the doping, transverse field, and velocity saturation dependencies [28], are activated in the simulation. The density gradient based quantization model that determines the quantum confinement effect in UTBs and narrow fins are also considered in the simulation, and the high- $k$ related mobility degradation effects are dealt with the Lombardi high- $k$ model. The inversion layer mobility model Lombardi (constant voltage and temperature, CVT) [29], along with the ShockleyReadHall (SRH) [30], [31] and Auger recombination models are included. The silicon bandgap narrowing model that determines the intrinsic carrier concentration is used for device simulation. A set of partial differential equations for the modeled device are solved self-consistently on the discrete mesh in an iterative fashion. All device simulation is 
performed at room temperature under the appropriate biasing conditions and the reported robust mesh generation procedure is used to generate all the simulation structures and the robustness of the structures against the sensitivity of grid spacings has been verified for accurate device simulation [6], [32].

The transient and ion strike simulations are performed using the Sentaurus HeavyIon module [24] for all cases by considering the ion track as a Gaussian shape. The heavy ion track parameters and models are used for inducing transient drain current by striking the ion in the sensitive areas of the device. The proposed devices are simulated in the off-state (more sensitive area) i.e., at $V_{G S}=0.0 \mathrm{~V}$ and $V_{D S}=0.7 \mathrm{~V}$. The impact of variation in ion track radius and characteristic time on the radiation sensitivity of the devices are also analyzed. Whenever the ion strikes vertically i.e., from the top of the gate of the devices, the charge is deposited in the vicinity of its track, the deposited charge is then rapidly transported by drift and diffusion mechanisms [33] and collected at the drain contact. The transient drain current due to the collected charge is calculated accurately by integrating the current for the duration of the transient time. The Bipolar amplification, defined as the ratio between the collected and deposited charges, characterizes the sensitivity of the devices [34].

\section{PERFormance EVAluation}

\section{A. Static Operation}

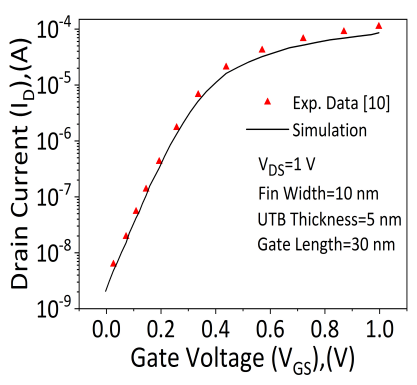

(a)

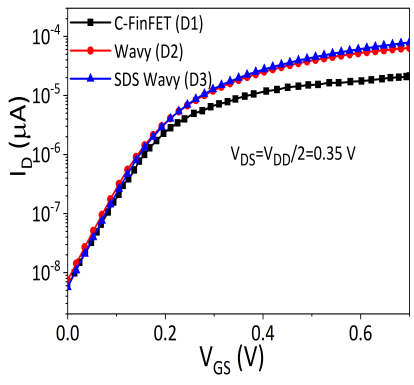

(b)
Fig. 2. (a) Simulated $I_{D}-V_{G S}$ characteristic of Wavy FinFET device at $V_{D S}=1.0 \mathrm{~V}$ matched with the data from Fig. 2 of experimental data [10]; the simulation data are obtained by calibrated simulation tools used in this study (b) $I_{D}-V_{G S}$ among the proposed devices, conventional FinFET (D1), Wavy FinFET (D2), and SDS Wavy FinFET (D3). An approximate threshold voltage $\left(V_{t h}\right)$ is maintained for all the devices by tuning the gate metal work function. The characteristics obtained at $V_{D S}=V_{D D} / 2=0.35 \mathrm{~V}$.

The numerical process and device simulations allow crucial insights on the nature of semiconductor devices that can lead to new perceptions [24]. However, the simulation needs to be properly calibrated before designing any device. Hence, the validity of the simulator has been inspected by comparing the results with previous literature data [9]. From Fig. 2(a), it is notable that our simulation results are in good agreement with that of Zhang et al. [9]. The simulated steady-state drain current $\left(I_{D}\right)$ in the conventional FinFET (D1), Wavy FinFET (D2), and SDS Wavy FinFET (D3) is compared in Fig. 2.b). The values of $I_{D}$ in log scale are compared among all three devices at $V_{D S}=V_{D D} / 2$ to observe the static current. The drive current of any device plays an important role in high performance (HP) consumer applications. Hence, it is crucial to evaluate and analyze the values of $I_{D}$ for all the devices under study. Fig. 2(b) shows a clear benefit in the device performance by incorporating the advanced technologies in the conventional one. Fig. 2 b), clearly, shows that there is steady and systematic rise in $I_{D}$ with technology advancement i.e., $I_{D}$ is higher for $\mathrm{D} 2$ (UTB+Conventional FinFET) than D1 (Conventional FinFET) and it is highest for D3 (high$k$ spacer+UTB+conventional FinFET). This increase in $I_{D}$ is mainly due to the UTB layer (it turns on prior to the fin) and because of the use of larger $L_{h k}$, which further modulates the carrier concentration in the underlap region.

The transient response in the presence of heavy ion irradiation is presented in the following sub-sections under the biasing conditions at off state, $V_{G S}=0 \mathrm{~V}$ and $V_{D S}=0.7 \mathrm{~V}$.

\section{B. Transient Operation}

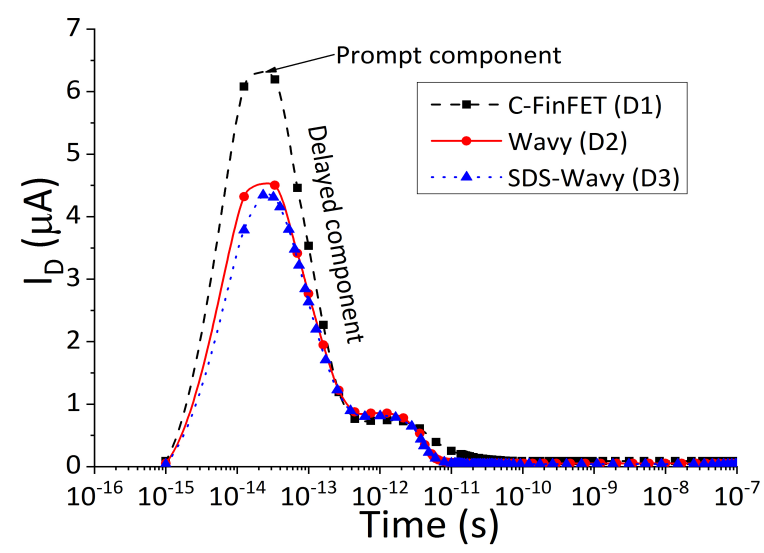

Fig. 3. Comparative analysis of the transient drain current with time among conventional FinFET (D1), Wavy FinFET (D2), and SDS Wavy FinFET (D3). The $V_{G S}=0.0 \mathrm{~V}$ and $V_{D S}=0.7 \mathrm{~V}$. The LET of the heavy ion is defined as 10 $\mathrm{MeV} /\left(\mathrm{mg} / \mathrm{cm}^{2}\right)$.

This section describes the transient response of the devices by heavy ion irradiation and characterization of device sensitivity due to ionizing radiations. The analysis is performed by using a medium Linear Energy Transfer (LET) value of $10 \mathrm{MeV} /\left(\mathrm{mg} / \mathrm{cm}^{2}\right)$ with an ion track radius of $20 \mathrm{~nm}$. A wide range of simulation time is used to investigate both the displacement current and diffusion current [35] for all devices under study at a certain LET value.

In addition, the impact of ion track radius and $t_{\text {characteristic }}$ on transient behavior has also, been investigated.

In this study, the transient drain current is induced due to the disturbance of electron density after ion strike at the middle of the channel [36], [37] by an LET of $10 \mathrm{MeV} /\left(\mathrm{mg} / \mathrm{cm}^{2}\right)$ [38] as shown in Fig. 3 The distortion of depletion region of the P-N junction along the ion track is known as funnel [18]. The collected electrons at the drain contact leads to current transient which toggles the logic state of the device. This induced current is due to drift and diffusion of carriers created after the formation of funnel. The drift current is due to the electron-hole pair generation inside the funnel, 


\begin{tabular}{|c|c|c|c|}
\hline & Before ion strike & After ion strike at $\mathrm{t}=10 \mathrm{ps}$ & After ion strike at $\mathrm{t}=100 \mathrm{ps}$ \\
\hline $\begin{array}{l}\text { Conventi } \\
\text { onal } \\
\text { FinFET } \\
\text { (D1) }\end{array}$ & & & $\begin{array}{ll} & \text { eDensity }\left(\mathrm{cm}^{\wedge}-3\right) \\
1.0 \mathrm{e}+20 \\
2.0 \mathrm{e}+18 \\
5.2 \mathrm{e}+16 \\
1.2 \mathrm{e}+15 \\
2.7 \mathrm{e}+15 \\
6.3 \mathrm{e}+11 \\
1.4 \mathrm{e}+10 \\
\end{array}$ \\
\hline $\begin{array}{l}\text { Wavy } \\
\text { FinFET } \\
\text { (D2) }\end{array}$ & & & \begin{tabular}{|l}
$5.4 \mathrm{e}+17$ \\
$1.4 \mathrm{e}+15$ \\
$4.0 \mathrm{e}+12$ \\
$1.0 \mathrm{e}+10$ \\
$2.9 \mathrm{e}+07$ \\
$8.1 \mathrm{e}+04$ \\
\end{tabular} \\
\hline $\begin{array}{c}\text { SDS } \\
\text { Wavy } \\
\text { FinFET } \\
\text { (D3) }\end{array}$ & & & $\begin{array}{l}1.9 \mathrm{e}+20 \\
5.4 \mathrm{e}+17 \\
1.4 \mathrm{e}+15 \\
4.0 \mathrm{e}+12 \\
1.1 \mathrm{e}+10 \\
3.0 \mathrm{e}+07 \\
8.3 \mathrm{e}+04 \\
\end{array}$ \\
\hline
\end{tabular}

Fig. 4. The 3-D profile of electron density (e-Density) before ion strike, after ion strike at $\mathrm{t}=10 \mathrm{ps}$, and $\mathrm{t}=100 \mathrm{ps}$ for conventional FinFET (D1), Wavy FinFET (D2), and SDS Wavy FinFET (D3). Only Fin and UTB (for hybrid devices) regions are shown for better visualization. The simulation is carried out at the off-state $i . e$. , at $V_{G S}=0.0 \mathrm{~V}$ and $V_{D S}=0.7 \mathrm{~V}$ and the ion strike $\mathrm{LET}=10 \mathrm{MeV} /\left(\mathrm{mg} / \mathrm{cm}^{2}\right)$.

which also termed as prompt current component. And, the diffusion current i.e., delayed current component, is because of the free electrons beneath the funnel. The component of delayed current is much smaller than that of prompt current as observed from Fig. 3. While comparing among all devices, the hybrid devices predict significantly low transient current tails compared to the conventional FinFETs due to stronger control over the channel. And, the improvement in the transient behavior with regards to time, the D3 is the optimum one.

Fig. 4 shows the 3-D profiles of electron density before and after the ion strike. The location of ion strike is exactly at the middle of the channel i.e., equidistant from the drain and source regions (drain-channel-source is the order of sequence represented in Fig. 47. For better visualization, the spacers, contacts, gate oxide, and BOX layer are not shown in Fig. 4 The ion strikes at an LET of $10 \mathrm{MeV} /\left(\mathrm{mg} / \mathrm{cm}^{2}\right)$ on the devices at off-state with $V_{G S}=0 \mathrm{~V}$ and $V_{D S}=0.7 \mathrm{~V}$. It is observed from Fig. 4 that the charge density decreases with time for all the devices after ion strike due to the charge transport and carrier recombination mechanisms. It is to be noted that the charge is collected at the drain contact after the ion strike. And, due to the introduction of the UTB layer in D2 and D3 devices, the value of the current density is higher than that for the D1 devices thus improving the carrier transport efficiency for D2 and D3 devices.

Fig. 5 shows the 3-D ion track profile in the entire fin and UTB region (hybrid case) for all devices with an ion strike at the middle of channel by LET of $10 \mathrm{MeV} /\left(\mathrm{mg} / \mathrm{cm}^{2}\right)$. An ion strikes the device in a vertical incidence to the gate and its track is not entirely contained in the active area of the device as shown in Fig. 5. The deposited charge due to ion track is obtained by considering a Gaussian distribution of the ion track at the exact location of the track within the silicon film thickness. A strong ion generation is observed in the UTB layer for hybrid devices that influences the deposited charge and consequently the bipolar amplification for the D2 and D3 devices.

In order to study the effect of heavy ion irradiation on semiconductor devices, the analysis of the $t_{\text {characteristic }}$ and ion track radius with the impact of variation of these parameters on the transient behavior of the devices are crucial. Fig. 6, 7, and 8 show the variation of $I_{D}$ for different $t_{\text {characteristic }}$ and ion track radius for the devices D1, D2, and D3, respectively. Since the ion strikes at the middle of the channel, all other heavy ion parameters are unchanged. From Fig. 6(a), 7(a), and 8 (a), it is observed that for all devices, the "prompt" current of the transient $I_{D}$ is narrow for $t_{\text {characteristic }}$ of $0.5 \mathrm{ps}$ compared to that for 2 ps. However, the transient current tails are almost the same for both $(2 \mathrm{ps}$ and $0.5 \mathrm{ps}) t_{\text {characteristic }}$ cases. In a similar way, the impact of ion track radius on the transient response for all three device cases is also studied as shown in Fig. 6(b), 7(b), and 8(b). For the previous analysis, a narrow ion track radius of $20 \mathrm{~nm}$ is considered. Hence, the simulations are performed for the extraction of transient drain current with radius of $70 \mathrm{~nm}$ and the results are compared with $20 \mathrm{~nm}$ ion track radius. From Fig. 6(b), 7 (b), and 8(b), the transient tails are much higher for low ion track radius values $(20 \mathrm{~nm})$. At high ion track radius of $70 \mathrm{~nm}$, the drain current peaks are very low indicating a less charge deposition in the channel region compared to source/drain regions. Hence, the collected charge decreases with the increase of ion track radius, which is further favorable for a lower bipolar amplification. After closely observing the transients for all devices, the D3 device is showing the least transient values compared to D1 and D2. 


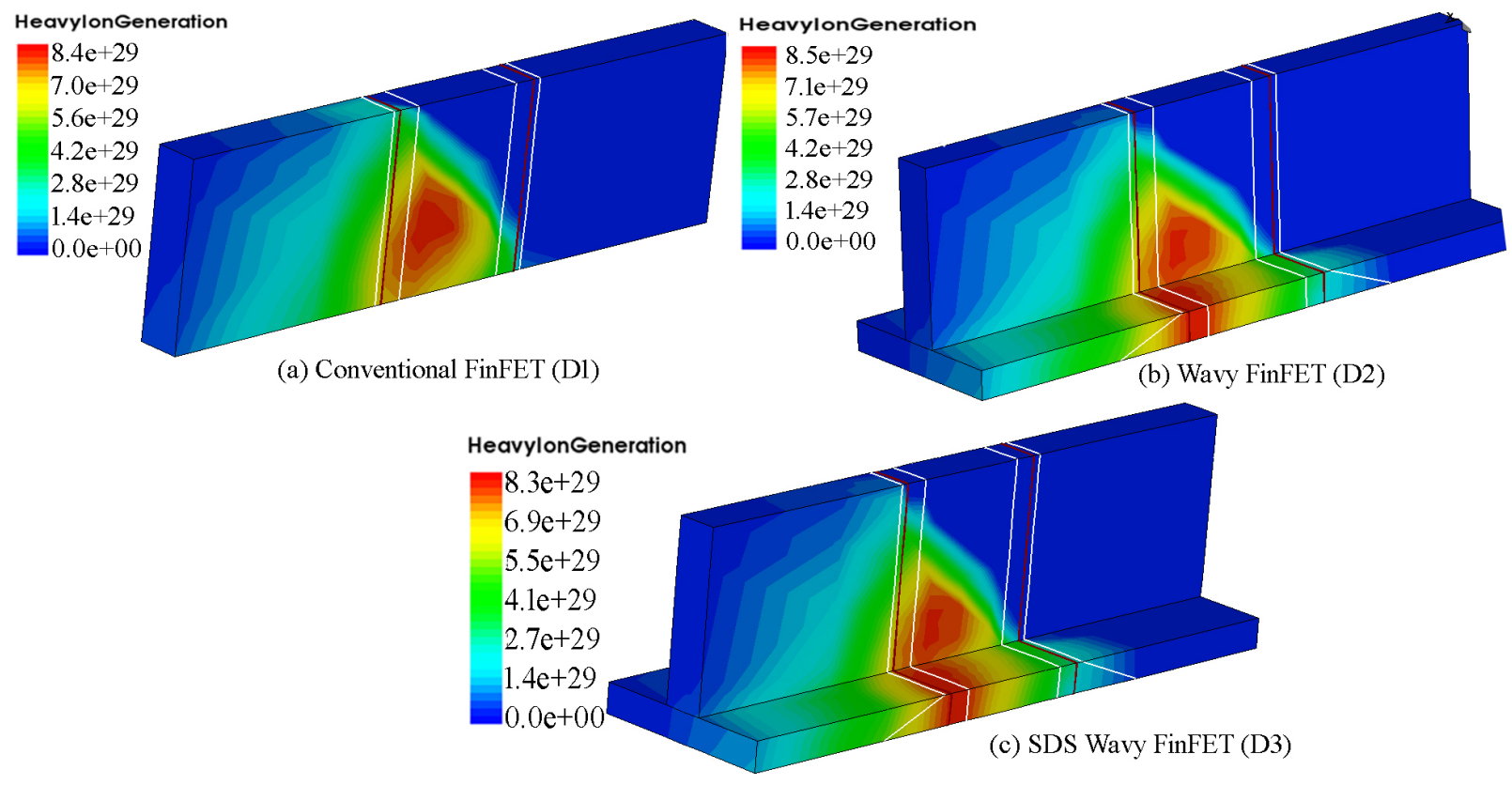

Fig. 5. The 3-D profile of heavy ion generation after ion strike for (a) Conventional FinFET (D1), (b) Wavy FinFET (D2), and (c) SDS Wavy FinFET (D3). Only Fin and UTB (for hybrid devices) regions are shown for better visualization. The $V_{G S}=0.0 \mathrm{~V}$ and $V_{D S}=0.7 \mathrm{~V}$. The LET of the heavy ion is defined as $10 \mathrm{MeV} /\left(\mathrm{mg} / \mathrm{cm}^{2}\right)$.

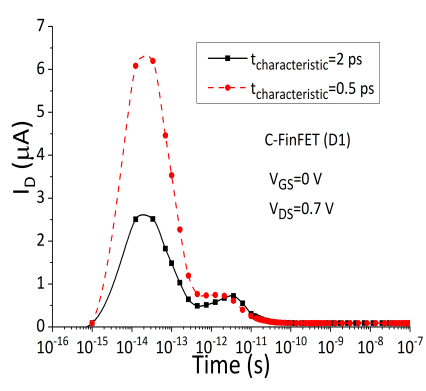

(a)

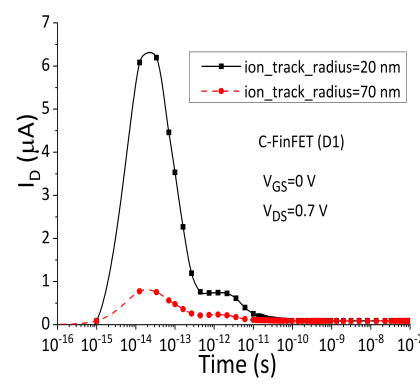

(b)

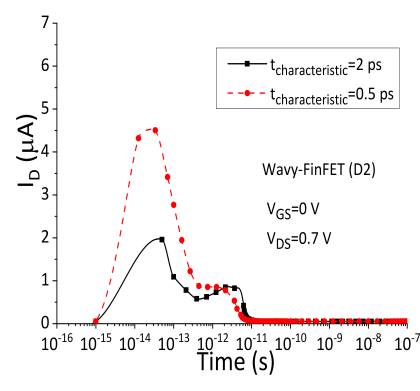

(a)

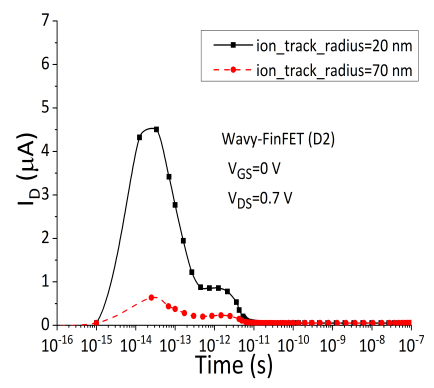

(b)

Fig. 6. The transient drain current with time for conventional FinFET (D1) with different (a) characteristic time $\left(t_{\text {characteristic }}\right)(\mathrm{b})$ ion track radius. The $V_{G S}=0.0 \mathrm{~V}$ and $V_{D S}=0.7 \mathrm{~V}$. The LET of the heavy ion is defined as 10 $\mathrm{MeV} /\left(\mathrm{mg} / \mathrm{cm}^{2}\right)$.

TABLE II

Comparative Analysis of Collected Charge (AREA under the Transient Current Curve) For All Three Proposed Devices AT $t_{\text {characteristic }}=0.5$ PS AND ION TRACK RADIUS $=20 \mathrm{NM}$

\begin{tabular}{|l|l|l|l|}
\hline Devices & $\begin{array}{l}\text { Conventional } \\
\text { FinFET (D1) }\end{array}$ & $\begin{array}{c}\text { Wavy } \\
\text { FinFET (D2) }\end{array}$ & $\begin{array}{c}\text { SDS Wavy } \\
\text { FinFET (D3) }\end{array}$ \\
\hline Collected Charge (C) & $8.768 \times 10^{-15}$ & $5.222 \times 10^{-15}$ & $4.165 \times 10^{-15}$ \\
\hline
\end{tabular}

For a better comparative analysis, the collected charge is evaluated by calculating the area under the transient current curves for all devices at $t_{\text {characteristic }}=0.5 \mathrm{ps}$ and ion track radius $=20 \mathrm{~nm}$, which is tabulated in Table II. By using the SDS Wavy FinFET, we can able to reduce the charge collection by an amount of $52.49 \%$ as compared to Conventional FinFET.

Finally, to observe the benefits of our proposed hybrid device over the conventional one, the bipolar amplification is examined for all devices. Initially, the collected charge is

Fig. 7. The transient drain current with time for Wavy FinFET (D2) with different (a) characteristic time $\left(t_{\text {characteristic }}\right)$ (b) ion track radius. The $V_{G S}=0.0 \mathrm{~V}$ and $V_{D S}=0.7 \mathrm{~V}$. The LET of the heavy ion is defined as 10 $\mathrm{MeV} /\left(\mathrm{mg} / \mathrm{cm}^{2}\right)$.

evaluated by integrating the transient drain current over a time period of $10^{-15}$ to $10^{-7}$ second for a particular ion tarck radius $(\mathrm{r}=20 \mathrm{~nm})$ and characteristic time $\left(t_{\text {characteristic }}=2 \mathrm{ps}\right)$ with certain LET value. Further, the collected charge is calculated at every instance of LET values (0.1-to-100 $\mathrm{MeV} /\left(\mathrm{mg} / \mathrm{cm}^{2}\right)$ ). And, the bipolar amplification is computed by taking the ratio between the collected charge and deposited charge for the duration of transient at each LET instance for bias condition $V_{G S}=0.0 \mathrm{~V}$, and $V_{D S}=0.7 \mathrm{~V}$. Fig. 9 shows the maximum of bipolar amplification for corresponding LET values for all three device architectures. The bipolar amplification is significantly lower for D3 device than D1 and D2. This is because of the lower charge collection for D3. For validation purpose, the simulation results are also matched with the inversion mode (IM)-double gate (DG) FET [39] for the LET values ranging from 10 to $100 \mathrm{MeV} /\left(\mathrm{mg} / \mathrm{cm}^{2}\right)$ and found our results are in agreement with [39]. Though the observation is 


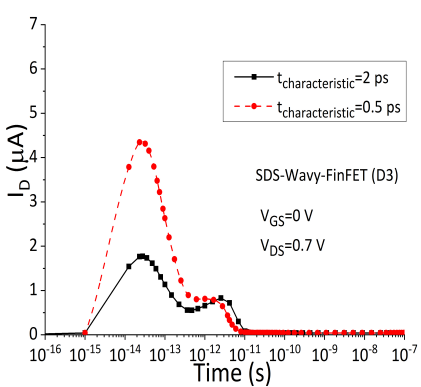

(a)

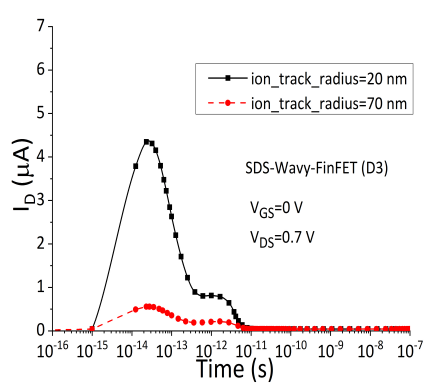

(b)
Fig. 8. The transient drain current with time for SDS Wavy FinFET (D3) with different (a) characteristic time $\left(t_{\text {characteristic }}\right)$ (b) ion track radius. The $V_{G S}=0.0 \mathrm{~V}$ and $V_{D S}=0.7 \mathrm{~V}$. The LET of the heavy ion is defined as 10 $\mathrm{MeV} /\left(\mathrm{mg} / \mathrm{cm}^{2}\right)$.

not so simple due to the difference in structural configurations. The results are compared for validation only.

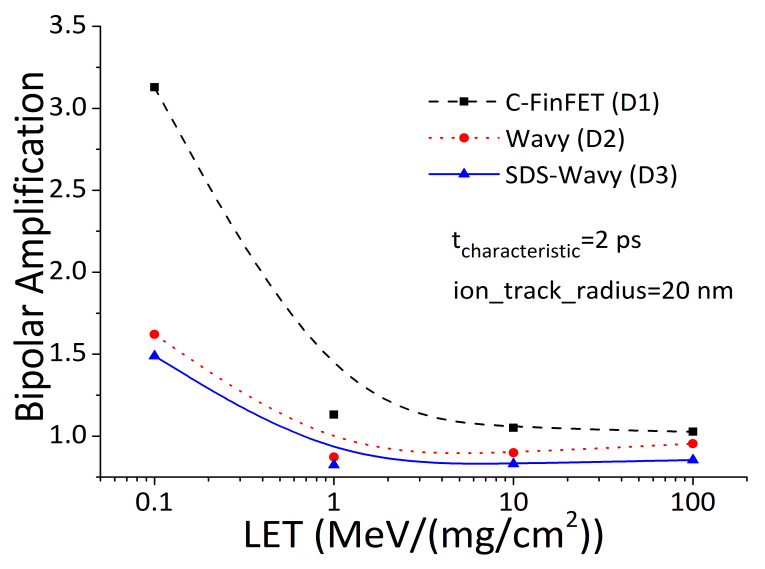

Fig. 9. The bipolar amplification as a function of LET for conventional FinFET (D1), Wavy FinFET (D2), and SDS Wavy FinFET (D3) in a comparative way. The $V_{G S}=0.0 \mathrm{~V}, V_{D S}=0.7 \mathrm{~V}$, ion track radius $=20 \mathrm{~nm}$, and $t_{\text {characteristic }}=2 \mathrm{ps}$.

\section{CONClusion}

This article presents the transient behavior of n-type hybrid devices i.e., Wavy FinFET (D2) and SDS Wavy FinFET (D3) for the first time. A detailed investigation has been performed to demonstrate the radiation sensitivity of various Fin-based devices by 3-D device simulation with Heavy Ion Irradiation model. Initially, the analysis is performed by striking the ion at the middle of channel with ion track radius and time $20 \mathrm{~nm}$ and $2 \mathrm{ps}$, respectively. The change in 3-D electron density profiles of the devices before and after the ion strike have been systematically investigated and compared with the conventional FinFETs (D1). Also, the transient current, heavy ion generation, and bipolar amplification are systematically examined for all three device architectures. In addition, the transient response of the devices in the off-state $\left(V_{G S}=0 \mathrm{~V}\right.$ and $V_{D S}=0.7 \mathrm{~V}$ ) has also been characterized by varying ion track time $\left(t_{\text {characteristic }}\right)$ and radius.

The simulated data show that the larger $t_{\text {characteristic }}$ and higher ion track radius decrease the transient $I_{D}$ that reduces the bipolar amplification. A strong ion generation and high current density is observed in the case of D2 and D3 devices compared to D1 due to the extra UTB layer. The D3 devices predict a very low transient $I_{D}$ resulting in an optimum bipolar amplification compared to D1 and D2. Considering the lower bipolar amplification of Wavy and SDS Wavy FinFET, these structures seem to be very promising devices for embedded system dedicated for harsh environments such as the space environment and civil nuclear environment.

\section{REFERENCES}

[1] S. K. Saha, Compact Models for Integrated Circuit Design: Conventional Transistors and Beyond. CRC Press, 2015.

[2] "Globalfoundries looks leapfrog fab rivals with new process," Tech. Rep., 2012.

[3] J. Kedzierski, M. Ieong, T. Kanarsky, Y. Zhang, and H. Wong, "Fabrication of metal gated finfets through complete gate silicidation with ni," Electron Devices, IEEE Transactions on, vol. 51, no. 12, pp. 2115-2120, 2004.

[4] Y. Li, H.-M. Chou, and J.-W. Lee, "Investigation of electrical characteristics on surrounding-gate and omega-shaped-gate nanowire finfets," Nanotechnology, IEEE Transactions on, vol. 4, no. 5, pp. 510-516, 2005.

[5] D. Hisamoto, W.-C. Lee, J. Kedzierski, H. Takeuchi, K. Asano, C. Kuo, E. Anderson, T.-J. King, J. Bokor, and C. Hu, "Finfet-a self-aligned double-gate mosfet scalable to $20 \mathrm{~nm}$," Electron Devices, IEEE Transactions on, vol. 47, no. 12, pp. 2320-2325, 2000.

[6] S. K. Mohapatra, K. P. Pradhan, D. Singh, and P. K. Sahu, "The Role of Geometry Parameters and Fin Aspect Ratio of sub-20nm SOI-FinFET: An Analysis towards Analog and RF Circuit Design," Nanotechnology, IEEE Transactions on, vol. 14, no. 3, pp. 546-554, 2015.

[7] P. K. Pal, B. K. Kaushik, and S. Dasgupta, "Investigation of Symmetric Dual-(k) Spacer Trigate FinFETs From Delay Perspective," Electron Devices, IEEE Transactions on, vol. 61, no. 11, pp. 3579-3585, 2014.

[8] L. Mathew et al., "Inverted t channel fet (itfet)-fabrication and characteristics of vertical-horizontal, thin body, multi-gate, multi-orientation devices, itfet sram bit-cell operation. a novel technology for $45 \mathrm{~nm}$ and beyond cmos." in IEEE Electron Devices Meeting, IEDM Technical Digest. IEEE, 2005, pp. 713-716.

[9] W. Zhang, J. G. Fossum, and L. Mathew, "The ITFET: A novel FinFETbased hybrid device," Electron Devices, IEEE Transactions on, vol. 53, no. 9, pp. 2335-2343, 2006.

[10] H. M. Fahad, A. M. Hussain, G. T. Sevilla, and M. Hussain, "Wavy channel transistor for area efficient high performance operation," Applied Physics Letters, vol. 102, no. 13, p. 134109, 2013.

[11] H. M. Fahad, C. Hu, and M. M. Hussain, "Simulation Study of a 3D Device Integrating FinFET and UTBFET," Electron Devices, IEEE Transactions on, vol. 62, no. 1, pp. 83-87, 2015.

[12] K. Pradhan and P. Sahu, "Benefits of asymmetric underlap dual-k spacer hybrid finfet over bulk finfet," IET Circuits, Devices \& Systems, vol. 10, no. 5, pp. 441-447, 2016.

[13] K. P. Pradhan, Priyanka, Mallikarjunarao, and P. K. Sahu, "Exploration of Symmetric High-k Spacer (SHS) Hybrid FinFET for High Performance Application," Superlattices and Microstructures, vol. 90, pp. 191197, 2016.

[14] K. Pradhan, Priyanka, and P. Sahu, "Temperature dependency of double material gate oxide (dmgo) symmetric dual-k spacer (sds) wavy finfet," Superlattices and Microstructures, vol. 89, pp. 355-361, 2016.

[15] L. Artola et al., "Seu prediction from set modeling using multi-node collection in bulk transistors and srams down to the $65 \mathrm{~nm}$ technology node," IEEE Transactions on Nuclear Science, vol. 58, no. 3, p. 1338, 2011.

[16] "Overall Roadmap Technology Characteristics, ITRS, 2013," Tech. Rep., 2013. [Online]. Available: http://www.semiconductors.org/clientuploads/ Research_Technology/ITRS/2013/2013Overview.pdf

[17] S. Mitra, P. Sanda, and N. Seifert, "Soft errors: technology trends, system effects, and protection techniques," in 13th IEEE International On-Line Testing Symposium (IOLTS 2007). IEEE, 2007, pp. 4-4.

[18] J.-P. Colinge, Silicon-on-Insulator Technology: Materials to VLSI: Materials to Vlsi. Springer Science \& Business Media, 2004.

[19] C. Vial, J. Palau, J. Gasiot, M. Calvet, and S. Fourtine, "A new approach for the prediction of the neutron-induced seu rate," IEEE transactions on Nuclear Science, vol. 45, no. 6, pp. 2915-2920, 1998. 
[20] M. Raine, G. Hubert, M. Gaillardin, L. Artola, P. Paillet, S. Girard, J.-E. Sauvestre, and A. Bournel, "Impact of the radial ionization profile on see prediction for soi transistors and srams beyond the 32-nm technological node," IEEE Transactions on Nuclear Science, vol. 58, no. 3, pp. 840 $847,2011$.

[21] J. Ahlbin, M. Gadlage, D. Ball, A. Witulski, B. Bhuva, R. Reed, G. Vizkelethy, and L. Massengill, "The effect of layout topology on single-event transient pulse quenching in a $65 \mathrm{~nm}$ bulk cmos process," IEEE Transactions on Nuclear Science, vol. 57, no. 6, pp. 3380-3385, 2010.

[22] P. Francis, J.-P. Colinge, and G. Berger, "Temporal analysis of seu in soi/gaa srams," IEEE Transactions on Nuclear Science, vol. 42, no. 6, pp. 2127-2137, 1995 .

[23] K. P. Pradhan, S. K. Saha, P. K. Sahu, and Priyanka, "Impact of fin height and fin angle variation on the performance matrix of hybrid finfets," IEEE Transactions on Electron Devices, vol. 64, no. 1, pp. 1-6, 2017.

[24] T. Sentaurus and G. Version, "Synopsys Inc," Mountain View, CA, 2013.

[25] C. Hu, "SOI and nanoscale MOSFETs," in Device Research Conference, 2001. IEEE, 2001, pp. 3-4.

[26] C.-H. Choi, P. Chidambaram, R. Khamankar, C. F. Machala, Z. Yu, and R. W. Dutton, "Gate length dependent polysilicon depletion effects," IEEE Electron Device Letters, vol. 23, no. 4, pp. 224-226, 2002.

[27] P. K. Pal, B. K. Kaushik, and S. Dasgupta, "Asymmetric dual-spacer trigate finfet device-circuit codesign and its variability analysis," Electron Devices, IEEE Transactions on, vol. 62, no. 4, pp. 1105-1112, 2015.

[28] C. Canali, G. Majni, R. Minder, and G. Ottaviani, "Electron and hole drift velocity measurements in silicon and their empirical relation to electric field and temperature," IEEE Transactions on Electron Devices, vol. 22, no. 11, pp. 1045 - 1047, 1975.

[29] C. Lombardi, S. Manzini, A. Saporito, and M. Vanzi, "A physically based mobility model for numerical simulation of nonplanar devices," IEEE Transactions on Computer-Aided Design of Integrated Circuits and Systems, vol. 7, no. 11, pp. 1164 - 1171, 1988.

[30] W. Shockley and W. T. Read, "Statistics of the Recombination of Holes and Electrons," Physical Review, vol. 87, pp. 835-842, 1952.

[31] R. N. Hall, "Electron-Hole Recombination in Germanium," Phys. Rev., vol. 87 , p. 387,1952

[32] S. K. Saha, "Introduction to technology computer aided design," Technology Computer Aided Design: Simulation for VLSI MOSFET, p. 1 2013.

[33] D. Munteanu and J.-L. Autran, "Modeling and simulation of singleevent effects in digital devices and ics," IEEE Transactions on Nuclear Science, vol. 55, no. 4, pp. 1854-1878, 2008.

[34] D. Munteanu and J.-L. Autran, "3-d simulation analysis of bipolar amplification in planar double-gate and finfet with independent gates," IEEE Transactions on Nuclear Science, vol. 4, no. 56, pp. 2083-2090, 2009.

[35] L. Artola, G. Hubert, S. Duzellier, and F. Bezerra, "Collected charge analysis for a new transient model by tcad simulation in $90 \mathrm{~nm}$ technology," IEEE Transactions on Nuclear Science, vol. 57, no. 4, p. $1869,2010$.

[36] L. Artola, G. Hubert, and R. Schrimpf, "Modeling of radiation-induced single event transients in soi finfets," in Reliability Physics Symposium (IRPS), 2013 IEEE International. IEEE, 2013, pp. SE-1.

[37] D. Ball, M. Alles, R. Schrimpf, and S. Cristoloveanu, "Comparing single event upset sensitivity of bulk vs. soi based finfet sram cells using tcad simulations," in SOI Conference (SOI), 2010 IEEE International. IEEE, 2010, pp. 1-2.

[38] S. Jagannathan, M. J. Gadlage, B. L. Bhuva, R. D. Schrimpf, B. Narasimham, J. Chetia, J. R. Ahlbin, and L. W. Massengill, "Independent measurement of set pulse widths from n-hits and p-hits in 65-nm cmos," IEEE Transactions on Nuclear Science, vol. 57, no. 6, pp. 3386-3391, 2010.

[39] D. Munteanu and J.-L. Autran, "Investigation of sensitivity to heavyion irradiation of junctionless double-gate mosfets by 3-d numerical simulation," 2014.

[40] D. Munteanu, V. Ferlet-Cavrois, J. Autran, P. Paillet, J. Baggio, O. Faynot, C. Jahan, and L. Tosti, "Investigation of quantum effects in ultra-thin body single-and double-gate devices submitted to heavy ion irradiation," IEEE transactions on nuclear science, vol. 53, no. 6 , pp. 3363-3371, 2006

K P Pradhan received the M.Tech

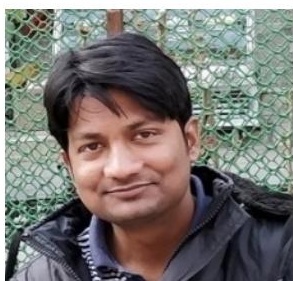
(Res) and Ph.D. degree in Nanoelectronic Devices, Electrical Engineering Department from National Institute of
Technology (NIT), Rourkela, Odisha, India, in 2013 and 2017, respectively. Next he worked as Senior Project Engineer at Nanolab, IIT Kanpur. He is also recipient of Snigdhashri Patra Memorial Gold Medal for the best PhD thesis of

\section{6-17 by NIT Rourkela.}

$\mathrm{He}$ is currently working as an Assistant Professor in the Department of ECE, Indian Institute of Information Technology, Design and Manufacturing (IIITDM), Kancheepuram, Chennai, India.

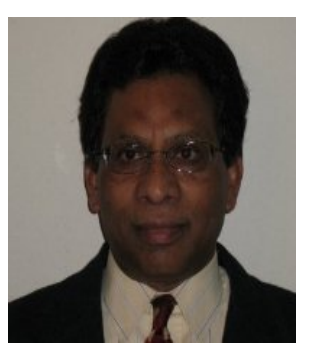

Samar K. Saha received the Ph.D. degree in physics from Gauhati University, Guwahati, India, and the M.S. degree in engineering management from Stanford University, Stanford, CA, USA. He is currently with the Prospicient Devices, Milpitas, CA 95035 USA and an Adjunct Professor with the Department of Electrical Engineering, Santa Clara University, Santa Clara.

Laurent Artola has graduated his M.S

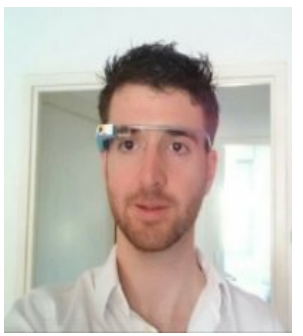
at University of Montpellier in 2007. Next, he worked at NXP Semiconductor at IMEC, Belgium on the variability of integrated FinFET transistors. In fall 2011, he defended his $\mathrm{PhD}$ and received the award of the best 2011 ONERA PhD in physics thematic. Since 2012, he is a researcher engineer at ONERA. He continue to work using combined TCAD and circuit simulators dedicated on the Single Event Effects (SEE) prediction and modeling in advanced electronics and systems.

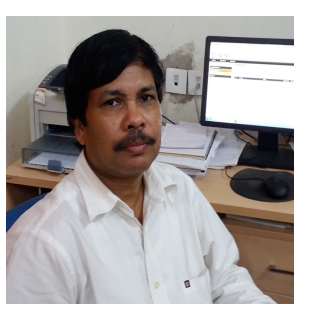

P.K. Sahu received the M.Sc. Engineering in Electronic Systems and Communication specialization from Sambalpur University, Odisha, India, and subsequently received Ph.D degree from Jadavpur University, Kolkata, India, in the year 2007. Currently he is Professor in the department of Electrical Engineering at National Institute of Technology,
Rourkela, Odisha, India. 